\title{
Comparison of one step glucose tolerance test (75 g GTT) and two step glucose tolerance test (100 g GTT) in screening and diagnosis of gestational diabetes mellitus
}

\author{
Saranya N., Suganthi M.*, Shanthi Dhinakaran, Navina N.
}

Department of Obstetrics and Gynecology, A. C. S. Medical College and Hospital, Chennai, Tamil Nadu, India

Received: 22 October 2018

Accepted: 29 October 2018

*Correspondence:

Dr. Suganthi M.,

E-mail: suganthipmadhesh@gmail.com

Copyright: () the author(s), publisher and licensee Medip Academy. This is an open-access article distributed under the terms of the Creative Commons Attribution Non-Commercial License, which permits unrestricted non-commercial use, distribution, and reproduction in any medium, provided the original work is properly cited.

\begin{abstract}
Background: Studies suggesting that increasing carbohydrate intolerance among patients not meeting the criteria for the diagnosis of GDM by two step OGTT leads to an increased rate of unfavourable maternal and perinatal outcomes. Patients with abnormal GCT results but a normal OGTT are at increased risk, as are those with one abnormal OGTT value rather than the two required for diagnosis by ADA criteria. Single value of one step GTT is enough to diagnose GDM and to improve the maternal and perinatal complications. The objective is to compare the efficacy of one step OGTT with two step OGTT in screening and diagnosis of gestational diabetes mellitus.

Methods: Hospital based analytical cross-sectional study which was conducted for 1 year among all pregnant women booked at government medical college, Alappuzha. They were subjected to detect GDM by 2 methods at 24-28 weeks.

Results: 2521 pregnant women were subjected for study, among them who were either 75 gm GTT or 50 gm GCT or both positive (332 pregnant women) were analyzed. 232 women $(69.88 \%$ ) were diagnosed as having gestational diabetes mellitus (GDM) by single step 75 gm GTT. Sensitivity of single step GTT was $92.4 \%$ and a false negative rate of the same was $7.6 \%$. False negative rate for 50 gm GCT was $35.2 \%$.

Conclusions: Present study concluded that this one step procedure is feasible in terms of better detection rates, saving time, limiting cost on repeated visits to health centre and reducing repeated invasive sampling. Single step GTT will be used both as a screening and a diagnostic procedure for detecting GDM.
\end{abstract}

Keywords: Fasting plasma glucose, Gestational diabetes mellitus, Glucose challenge test, Oral glucose tolerance test

\section{INTRODUCTION}

Gestational diabetes mellitus (GDM) is defined as varying severity of glucose intolerance with an onset or first recognition during the current pregnancy, regardless of whether insulin or diet modification is used for the treatment. ${ }^{1}$ The significance of GDM is that both the mother and the fetus are at increased risk of developing diabetes in their future life. During pregnancy, increasing maternal carbohydrate intolerance without GDM is also having direct association with both short and long term adverse maternal and fetal outcomes. ${ }^{2}$ Universal screening of all pregnant women for GDM identifies more number of cases than selective screening along with improvement in maternal and offspring outcome. ${ }^{3}$ In the Indian population, all pregnant women should be screened for GDM as the Indian females have an eleven fold higher risk of developing impaired glucose tolerance in the pregnancy than Caucasian females. ${ }^{4}$ Another important area of concern is that, ethnically also the Indian women have the highest frequency of developing GDM. $^{5}$ According to recent data, $16.55 \%$ is the 
prevalence of GDM in India. ${ }^{6}$ ADA recommends twostep procedure whereas WHO and DIPSI suggest that one-step 75g OGTT. The detection rate of WHO criteria is three times higher than ADA criteria which will be suitable for our Indian scenario. Studies have shown that this one step procedure is feasible because of better detection rates, saving time, limiting cost on repeated visits to hospital and reducing repeated invasive sampling.

\section{METHODS}

This study was carried out in the Government TD Medical College and Hospital, Alappuzha. Two thousand five hundred and twenty-one pregnant women who booked at TDMC were subjected to detect GDM by the following 2 methods at 24-28 weeks of pregnancy after informed consent.

$50 \mathrm{~g}$ oral glucose load was given irrespective of the meal status for glucose challenge test (GCT) and after 1 hour the venous blood samples were collected. ${ }^{7}$ Details included in the proforma were obtained, and the blood pressure measurement and the body mass index were recorded. All of them irrespective of the value after GCT were requested to come after 72 hours in the fasting state for the $75 \mathrm{~g}$ oral glucose tolerance test (OGTT) blood was drawn after 2 hours. ${ }^{8}$ The plasma glucose was assessed by glucose oxidation and peroxidation (GOD-POD) method.

\section{Diagnosis of GDM}

In the first method, if the venous plasma glucose value $\geq 140 \mathrm{mg} \%$ she will be subjected to 100 gm GTT. Blood glucose in the fasting state and after $100 \mathrm{gm}$ of oral glucose in 1 hour, 2 hours and 3 hours will be estimated. If two or more of the blood concentrations met or exceeded the glucose levels given below, diagnosis of GDM will be confirmed.

\section{ADA/ Carpenter Coustan (mg/dL)}

- $\quad$ Fasting $=95 \mathrm{mg} / \mathrm{dL}$

- 1 hour $=180 \mathrm{mg} / \mathrm{dL}$

- 2 hours $=155 \mathrm{mg} / \mathrm{dL}$

- 3 hours $=140 \mathrm{mg} / \mathrm{dL}$

In the second method, if the venous blood concentration, $\geq 200$-pre-gestational diabetes and >140-199 gestational diabetes. $^{8}$

\section{Methodology}

Study population analysed were,

- Those that were $50 \mathrm{gm}$ GCT positive and $100 \mathrm{gm}$ GTT either positive or negative,

- $\quad 75$ gm GTT positive either alone or in combination with previous criteria.
Women who were negative for both 50 gm GCT and 75 gm GTT were excluded from the analysis. Sensitivity and specificity of $75 \mathrm{gm} \mathrm{GTT}$ is analyzed using $100 \mathrm{gm}$ GTT as gold standard.

\section{RESULTS}

All antenatal women attending obstetrics OPD at 24-28 weeks, who met the criteria and willing for the study were included. Among them 332 women were found to be positive with either $50 \mathrm{gm}$ GCT/ $75 \mathrm{gm}$ GTT positive. Out of these 332 positive pregnant women, 232 were 75 gm GTT positive and 100 were negative (Table 1). In those 100 negative pregnant women, 18 were diagnosed as gestational diabetes by two step GTT. False negative rate of single step GTT was $7.6 \%$.

Table 1: 75 g GTT.

\begin{tabular}{|lll|}
\hline & Frequency & Percentage \\
\hline Positive & 232 & 69.9 \\
\hline Negative & 100 & 30.1 \\
\hline & 332 & 100.0 \\
\hline
\end{tabular}

In 144 women, both 50 gm GCT (screening) and $75 \mathrm{gm}$ GTT were positive (Table-2), screen positive women underwent 100 gm GTT. By 100 gm GTT 77 (28.6\%) were diagnosed to have gestational diabetes and 67 were not GDM (26.5\%). 100 women were screening test (50gm) positive and $75 \mathrm{gm}$ GTT negative, among them 18 were diagnosed as gestational diabetes by $100 \mathrm{gm}$ GTT.

Table 2: $50 \mathrm{~g}$ GCT and $75 \mathrm{~g}$ GTT.

\begin{tabular}{|ll|ll|} 
& & $\begin{array}{l}\text { Positive } \\
\text { GTT }(75 \mathrm{~g})\end{array}$ & $\begin{array}{l}\text { Negative } \\
\text { GTT (75 g) }\end{array}$ \\
\hline \multirow{2}{*}{ GCT (50 g) } & \begin{tabular}{l} 
Positive \\
\cline { 2 - 3 }
\end{tabular} & 144 & 100 \\
\cline { 2 - 3 } & Negative & 88 & E
\end{tabular}

E: Excluded from analysis

75 gm GTT missed that 18 women (7.2\%). Eighty-eight (88) women who were missed by 50 gm GCT were positive for $75 \mathrm{gm}$ GTT which showed a false negative rate of $35.2 \%$ for $50 \mathrm{gm} \mathrm{GCT} \mathrm{(Figure} \mathrm{1).}$

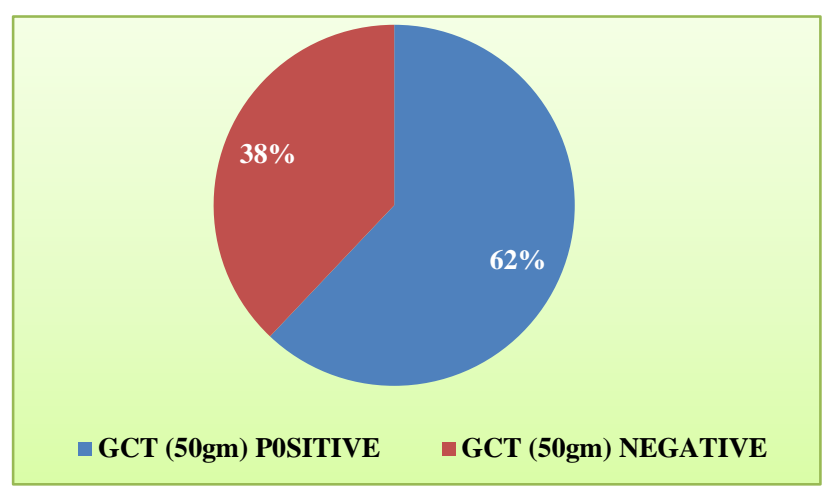

Figure 1: In 75 g GTT positive. 
232 pregnant women were diagnosed as gestational diabetes by $75 \mathrm{gm}$ single step GTT. In that, 88 was screen negative so they did not undergo $100 \mathrm{gm}$ GTT. Sixtyseven were negative by 2 step GTT and 77 were diagnosed as gestational diabetes by 100 gm GTT (Table 3). $155(46.69 \%)$ pregnant women missed by 2 step GTT were diagnosed as gestational diabetes by single step GTT.18 pregnant women missed by single step GTT were diagnosed as GDM by two step GTT.

Table 3: $75 \mathrm{~g}$ GTT and $100 \mathrm{~g}$ GTT.

\begin{tabular}{|c|c|c|c|c|}
\hline & & $\begin{array}{l}\text { Screen } \\
\text { negative }\end{array}$ & $\begin{array}{l}\text { Positive } \\
\text { GTT } \\
(100 \mathrm{~g})\end{array}$ & $\begin{array}{l}\text { Negative } \\
\text { GTT } \\
(\mathbf{1 0 0} \mathbf{g})\end{array}$ \\
\hline GTT & Positive & 88 & 77 & 67 \\
\hline$(75 \mathrm{~g})$ & Negative & $\mathrm{E}$ & 18 & 82 \\
\hline
\end{tabular}

E: Excluded from analysis

The mean age of the pregnant women in present study was $25 \pm 5$ years. The prevalence percentage has been increasing with age from $5.9 \%$ in the age group of $\leq 20$ years to $21.6 \%$ in the age group > 30 years (Figure 2).

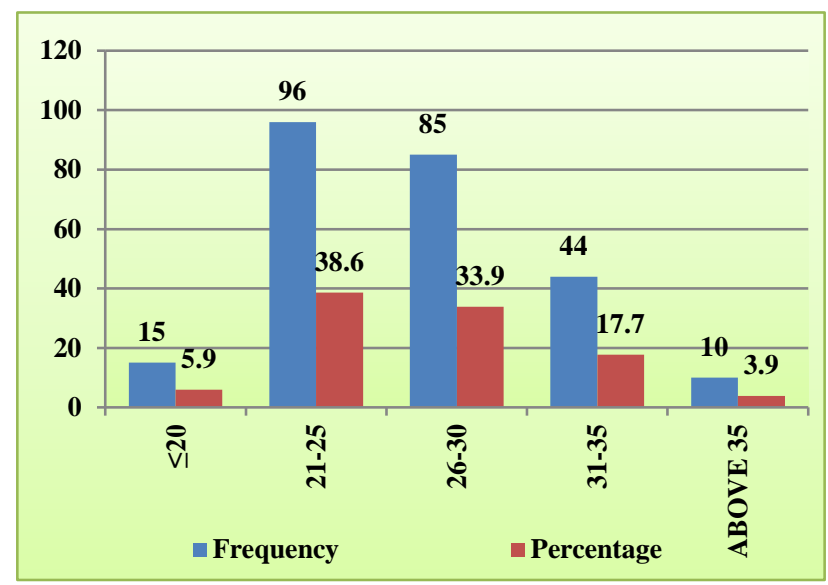

Figure 2: Age wise distribution of GDM.

The prevalence of GDM was more in primigravida $54.6 \%$ compared to third gravida $9.2 \%$ (Figure 3 ).

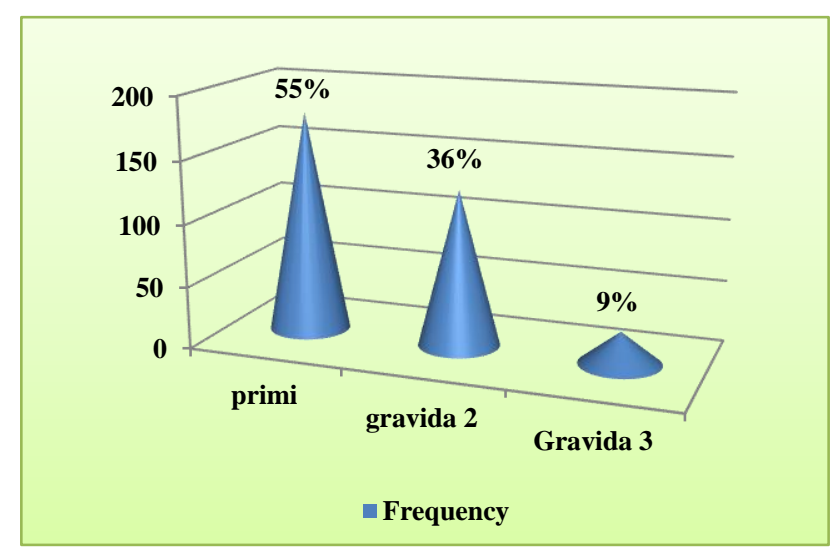

Figure 3: Obstetric score.

\section{DISCUSSION}

Gestational diabetes constitutes a metabolically distinct entity with definitely associated perinatal and maternal morbidities on short and long term. Hence, warrants timely diagnosis and prompt management. Authors now understand that there is a continuum of increasing carbohydrate intolerance associated with increased risk for adverse pregnancy outcomes. Authors were motivated to compare the one step GTT and two step GTT in screening and diagnosis of GDM and also analysed the maternal and perinatal outcome. Three thirty-two pregnant women were analysed.

In the two step GTT, the pregnant female have to visit the hospital more than once and give blood samples for 3 to 5 times. Single step GTT with $75 \mathrm{gm}$ of oral glucose and a 2-hour plasma glucose value of $\geq 140 \mathrm{mg} / \mathrm{dL}$ is used to diagnose GDM during pregnancy. This method serves both as screening and a diagnostic procedure which is recommended by WHO and DIPSI. It is easier to perform, is economical and has better compliance.

It was observed that the incidence of abnormal values were more in the low risk age group of 20-25 years. Seshiah et al study, same was $23 \pm 4$ years. ${ }^{9}$ No significant associations were observed between abnormal GCT / GTT values and educational or socioeconomic status, with more or less similar distribution among the different strata. Abnormal GCT/ GTT values and gestational diabetes were seen more in primigravidae $(54.6 \%)$ than multigravidae (9.2\%). This is much similar to the increased incidence of gestational diabetes noted among primigravidae. In contradictory, Seshiah et al study it was $16.3 \%$ among primi and $25.8 \%$ in multigravida. ${ }^{9}$

Sensitivity and false negative rate of $75 \mathrm{gm}$ GTT was $92.4 \%$ and $7.6 \%$ respectively. Slight higher false positive rate was also noted with 75 gm GTT but with diabetic diet if the blood sugar values were normal they were not intervened. Significant past history associated were primary infertility and PCOS. Large proportion had family history and previous obstetric history of diabetes mellitus although it was not significant.

Maternal hyperglycemia is directly related to increasing pregnancy morbidity and increased chance of developing diabetes in the mother. ${ }^{10,11}$ In addition, over the next 10 20 years, the number of reproductive group females with diabetes mellitus in the world will be approximately 80 million. Among them 20 million females will belongs to India and contribute to increased rates of maternal and infant morbidity. ${ }^{12}$

Regarding 50 g GCT, Magee et al reported that in their follow up among 457 screen positive pregnant women,91 failed to return for diagnostic test. ${ }^{13}$ De Aguiar et al study also $23 \%$ of screen positive individuals did not undergo OGTT. ${ }^{14}$ This non-compliant is due to the fact that the 
pregnant women have to attend the hospital for the 2 step GTT on more than one occasion.

In present study, $88(35.2 \%)$ pregnant women who were negative as per GCT screening were diagnosed having GDM. Seshiah et al study it was $21.5 \% .{ }^{9}$ Usually, OGTT will be done only for the pregnant women who were GCT screening positive, so they had been missed from diagnosis if 2 step GTT only followed for diagnosis. Actually, ADA criteria were validated against the risk of developing maternal diabetes in future but not evaluating the adverse perinatal outcome. Pettit also favored WHO recommendation in his study. ${ }^{15}$ Furthermore, in routine practice also single step GTT is preferred for detecting GDM. ${ }^{16,17}$

In present study the detection rate of GDM was $28.6 \%$ by applying ADA criteria whereas according to WHO criteria $69.9 \%$ and it was approximately 3 times more with WHO criteria than with ADA criteria. Schmidt et al study, the prevalence was $2.4 \%$ by using the ADA criteria and $7.2 \%$ by applying WHO criteria and diagnosed 3 times more GDM with WHO criteria. ${ }^{18}$ Seshiah et al study it was $3.9 \%$ and $16.2 \%$ respectively and the detection rate was 4 times than WHO criteria. ${ }^{9}$ Using single step GTT for identifying more number of cases and treating GDM effectively may prevent further complications, which have been confirmed by Meltzer et al also. ${ }^{18,19}$ From the above discussed factors along with published and discussed evidences establish the preference of WHO criteria than the ADA criteria.

Ethnically Indian females are more prevalent to develop diabetes and their risk for developing diabetes during the pregnancy is 11 times more than the White women, warrants the importance of screening all Indian pregnant women for abnormal glucose tolerance. ${ }^{4}$ The two step GTT is practically difficult as the pregnant women have to attend the clinic two times and 3 to 5 times blood samples had to be taken. Single step GTT, serves both as screening and a diagnostic procedure which is recommended by WHO and DIPSI. It is easier to perform, economical and has better compliance. Pregnant females with GDM are at an increased risk for developing adverse obstetric and perinatal outcomes. By early diagnosis, intervention and meticulous antenatal care feto maternal outcome will be optimized.

\section{CONCLUSION}

Present study concluded that this one step procedure is feasible in terms of better detection rates, saving time, limiting cost on repeated visits to health centre and reducing repeated invasive sampling. Single step GTT will be used both as a screening and a diagnostic procedure for detecting GDM.

Funding: No funding sources

Conflict of interest: None declared
Ethical approval: The study was approved by the Institutional Ethics Committee

\section{REFERENCES}

1. Dornhorst A, Rossi M. Risk and prevention of type 2 diabetes in women with gestational diabetes. Diabetes Care. 1998;21(Suppl2):B43-9.

2. Sermer M, Naylor CD, Farine D, Kenshole AB. The Toronto tri-hospital gestational diabetes project: A preliminary review. Diabetes care. 1998;21:B33-42.

3. Cosson E. Screening and insulin sensitivity in gestational diabetes. In Abstract volume of the $40^{\text {th }}$ Annual Meeting of the EASD 2004:A350.

4. Dornhorst A, Paterson CM, Nicholls JS, Wadsworth J, Chiu DC, Elkeles RS, et al. High prevalence of gestational diabetes in women from ethnic minority groups. Diabetic Medicine. 1992;9(9):820-5.

5. Beischer NA, Oats JN, Henry OA, Sheedy MT, Walstab JE. Incidence and severity of gestational diabetes mellitus according to country of birth in women living in Australia. Diabetes. 1991;40(Supplement 2):35-8.

6. Seshiah V, Balaji V, Balaji MS, Sanjeevi CB, Green A. Gestational diabetes mellitus in India. JAPI. 2004;52:707-11.

7. American Diabetic Association Clinical practice recommendations 2002. Diabetes care 2002;25(Suppl 1):147.

8. WHO study group prevention of diabetes mellitusGeneva. World health Organization. 1994 (Technical report series 844). Available at: https://onlinelibrary.wiley.com/doi/abs/10.1002/\%28 SICI\%2910969136\%28199604\%2913\%3A4\%3C392\%3A\%3AAI D-DIA81\%3E3.0.CO\%3B2-X.

9. Seshiah V, Balaji V, Balaji MS, Sekar A, Sanjeevi $\mathrm{CB}$, Green A. One step procedure for screening and diagnosis of gestational diabetes mellitus. Diabetes. 2005;126:200.

10. Dornhorst A, Beard RW. Gestational diabetes a challenge for the future. Diabet Med. 1993;10:897905.

11. Jarrett RJ. Gestational diabetes. Diabet Med. 1994;11:992-3.

12. Ramachandran A, Snehalatha C, Kapur A, Vijay V, Mohan V, Das AK, et al. Diabetes Epidemiology Study Group in India (DESI) 2001 High prevalence of diabetes and impaired glucose tolerance in India: National Urban Diabetes Survey. Diabetologia. 2001;44:1094-101.

13. Magee MS, Walden CE, Benedetti TJ, Knopp RH. Influence of diagnostic criteria on the incidence of gestational diabetes and perinatal morbidity. JAMA. 1993;269(5):609-15.

14. de Aguiar LG, de Matos HJ, de Brito Gomes M. Could fasting plasma glucose be used for screening high-risk outpatients for gestational diabetes mellitus?. Diabetes Care. 2001;24:954-5. 
15. Pettitt DJ. The $75 \mathrm{~g}$ oral glucose tolerance test in pregnancy. Diabetes Care. 2001;24:1129.

16. Pettitt DJ, Bennett PH, Hanson RL, Narayan KV, Knowler WC. Comparison of World Health Organization and National Diabetes Data Group procedures to detect abnormalities of glucose tolerance during pregnancy. Diabetes Care. 1994;17(11):1264-8.

17. Moses RG, Moses M, Russell KG, Schier GM. The 75-g glucose tolerance test in pregnancy: a reference range determined on a low-risk population and related to selected pregnancy outcomes. Diabetes Care. 1998;21(11):1807-11.

18. Schmidt MI, Duncan BB, Reichelt AJ, Branchtein L, Matos MC, e Forti AC, et al. Gestational diabetes mellitus diagnosed with a 2-h 75-g oral glucose tolerance test and adverse pregnancy outcomes. Diabetes Care. 2001;24(7):1151-5.

19. Meltzer SJ, Synder J, Morin L, Nudi M. Validation of normative data for $75 \mathrm{~g}$ oral glucose tolerance test (OGTT) in a Montreal pregnant population considering ethnicity. In: Matsdinsky FM, ed. Abstract book of the $64^{\text {th }}$ Scientific Sessions of the American Diabetes Association, Florida. American Diabetes Association; 2004:53:A19.

20. Cosson E, Benthimol M, Carbilon L, Paries J, Pharisien I, Valensi P, et al. Universal screening for gestational diabetes mellitus improves maternal and fetal outcomes compared with selective screening. In: Mateclinsky FM, ed. Abstract book of the $64^{\text {th }}$ Scientific Sessions of the American Diabetes. 2004;53:A61.

Cite this article as: Saranya N, Suganthi M, Dhinakaran S, Navina N. Comparison of one step glucose tolerance test (75 g GTT) and two step glucose tolerance test (100 g GTT) in screening and diagnosis of gestational diabetes mellitus. Int $\mathbf{J}$ Reprod Contracept Obstet Gynecol 2018;7:4814-8. 